\title{
Anthocyanins in blue berries of Vaccinium padifolium
}

\author{
Luis Cabrita, Øyvind M. Andersen* \\ Department of Chemistry, University of Bergen, Allégt. 41, 5007 Bergen, Norway
}

Received 16 December 1998; received in revised form 26 February 1999; accepted 3 March 1999

\begin{abstract}
Twenty anthocyanins were isolated from the extract of the edible blue berries of Vaccinium padifolium (Uveira) by a combination of chromatographic techniques. Mainly on the basis of nuclear magnetic resonance techniques $\left({ }^{1} \mathrm{H}\right.$, COSY, TOCSY, HSQC, HMBC, SEFT) they were identified as the 3-O- $\beta$-glucopyranosides, 3-O- $\beta$-galactopyranosides, 3-O- $\beta$ arabinopyranosides and 3-O-sambubiosides (2"-O- $\beta$-xylopyranosyl- $O$ - $\beta$-glucopyranosides) of delphinidin, cyanidin, petunidin, malvidin and peonidin. Anthocyanidin disaccharides have not been identified in the genus Vaccinium previously, and the 3sambubiosides of peonidin, petunidin and malvidin are novel compounds. (C) 1999 Elsevier Science Ltd. All rights reserved.
\end{abstract}

Keywords: Vaccinium padifolium; Ericaceae; Berries; Anthocyanins; Petunidin 3-sambubioside; Peonidin 3-sambubioside; Malvidin 3-sambubioside; Chemotaxonomy

\section{Introduction}

The genus Vaccinium in the family Ericaceae comprises about 200 species. Some species have edible fruits of economic importance. In the last decades the anthocyanin content of some Vaccinium species, especially $V$. myrtillus, has received interest due to their pharmacological properties, in particular effect on blood vessels and in ophthalmology (Morazzoni \& Bombardelli, 1996) and potential inhibition of HIV virus (Andersen \& Helland, 1995). From a chemotaxonomic point of view it has been suggested that the genus Vaccinium may be characterised by the general presence in its fruits of 3-monoglycosides in which the aglycones delphinidin, cyanidin, petunidin, malvidin and peonidin are combined with the sugars galactose, arabinose and glucose (Ballinger, Galetta \& Mannes, 1979). Many Vaccinium spp. have later been found to contain some or all of these anthocyanins. However, the repertoire has been extended by the identification of the 3-arabinoside and 3-galactoside of pelargonidin

\footnotetext{
* Corresponding author. Tel.: +47-55-583-460; fax: +47-55-589490.

E-mail address: oyvind.andersen@kj.uib.no (Ø.M. Andersen).
}

in berries of $V$. japonicum (Andersen, 1987) and the 3acetylglucoside and 3-acetylgalactoside of malvidin in V. angustifolium (Gao \& Mazza, 1995).

Vaccinium padifolium is a deciduous shrub endemic to Madeira island (Portugal). Its berries have been used as food preserves and in local ethnopharmacology (cough, colds, bronchitis, dysentery) (Rivera \& Obón, 1995) and exported for commercial production of ophthalmic specialities (Vieira, 1992). Its pigment content has previously not been reported, and the aim of this study is to present its complex anthocyanin content, including the first anthocyanidin disaccharides from this genus among which three are novel.

\section{Results and discussion}

The acidified methanolic extract obtained from $V$. padifolium berries contained a range of anthocyanins (Fig. 1). This extract was partitioned against ethyl acetate, washed on an Amberlite XAD-7 column, and chromatographed on a Sephadex LH-20 column. Pure anthocyanins were finally obtained after semi-preparative reverse-phase HPLC. The collected fractions were monitored by TLC and analytical HPLC. The fifteen 


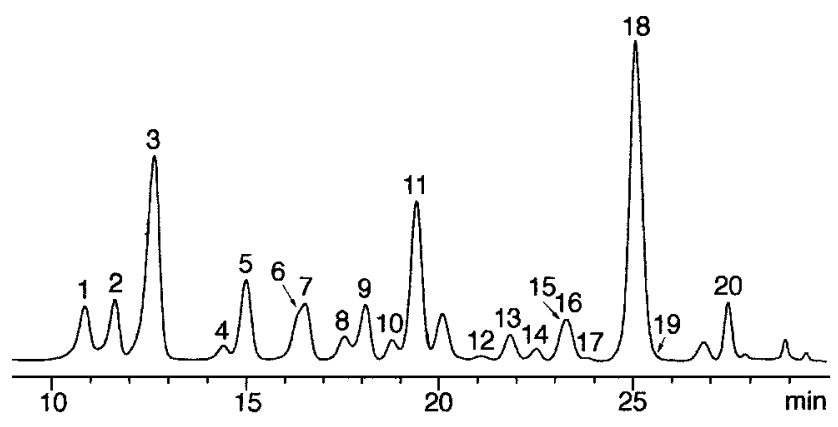

Fig. 1. HPLC profile of the crude anthocyanin extract of berries of Vaccinium padifolium detected at $520 \pm 20 \mathrm{~nm}$. See Table 1 for identification of peaks.

3-O-glucosides, 3-O-galactosides and 3-O-arabinosides of delphinidin, cyanidin, petunidin, peonidin and malvidin were identified on the basis of UV-VIS spectral data and cochromatography (TLC and HPLC) with known anthocyanins from $V$. myrtillus (Table 1).

The low-field part of the ${ }^{1} \mathrm{H}$ NMR spectrum of 9 showed six resonances (see Table 2). On the basis of chemical shifts and coupling-patterns the signals of the $\mathrm{AX}$ system at $\delta 7.83$ and 7.92 were assigned to $\mathrm{H}^{\prime}$ and $\mathrm{H} 6^{\prime}$, respectively, while the $3 \mathrm{H}$ AMX system at $\delta$ 6.96, 6.72 and 9.01 were assigned to $\mathrm{H}-8, \mathrm{H}-6$ and $\mathrm{H}-$

Table 1

Retention times (HPLC) and relative amounts of the anthocyanins in berries of Vaccinium padifolium

\begin{tabular}{lllc}
\hline Peak No. $^{\text {a }}$ & Anthocyanin & HPLC $t_{\mathrm{R}}(\mathrm{min})$ & Amount $(\%)^{\mathrm{c}}$ \\
\hline 1 & dp 3-gal & 10.8 & 3.8 \\
2 & dp 3-sam & 11.6 & 4.8 \\
3 & dp 3-glc & 12.6 & 17.7 \\
4 & cy 3-gal & 14.4 & 1.0 \\
5 & dp 3-ara & 14.9 & 6.0 \\
6 & cy 3-sam & 16.4 & 2.2 \\
7 & cy 3-glc & 16.5 & 3.5 \\
8 & pt 3-gal & 17.2 & 1.5 \\
9 & pt 3-sam & 18.1 & 5.4 \\
10 & cy 3-ara & 18.8 & 1.3 \\
11 & pt 3-glc & 19.4 & 13.0 \\
12 & pn 3-gal & 21.1 & nd \\
13 & pt 3-ara & 21.8 & 1.9 \\
14 & pn 3-sam & 22.5 & 0.7 \\
15 & pn 3-glc & 23.2 & 0.8 \\
16 & mv 3-gal & 23.3 & 2.4 \\
17 & mv 3-sam & 23.4 & nd \\
18 & mv 3-glc & 25.0 & 25.6 \\
19 & pn 3-ara & 25.2 & 0.9 \\
20 & mv 3-ara & 27.4 & 2.7 \\
\hline
\end{tabular}

\footnotetext{
${ }^{\mathrm{a}}$ See Fig. 1.

${ }^{\mathrm{b}} \mathrm{dp}$ means delphinidin, cy cyanidin, pt petunidin, pn peonidin, $\mathrm{mv}$ malvidin, gal galactoside, glc glucoside, ara arabinoside, sam sambubioside and nd not determined.

${ }^{\mathrm{c}}$ Unknowns: ca $5 \%$.
}

4, respectively. The HMBC spectrum of 9 showed crosspeaks between $\mathrm{H} 4 / \mathrm{C} 8(\delta 9.0 / 94.3), \mathrm{H} 6 / \mathrm{C} 4(\delta$ 6.6/ 135.4) and $\mathrm{H} 8 / \mathrm{C} 4(\delta 6.9 / 135.4)$. Together with the $3 \mathrm{H}$ singlet at $\delta 4.08(\mathrm{OMe})$, which in the $\mathrm{HMBC}$ spectrum correlated with $\mathrm{C} 3^{\prime}(\delta$ 4.1/148.9), these assignments confirmed the identity of the aglycone to be petunidin.

The anomeric proton signals in the ${ }^{1} \mathrm{H}$ NMR spectrum of 9 appear considerably downfield for the other sugar resonances, and thus the two doublets at $\delta 5.56$ and 4.78 together with the integration data defined the peonidin:sugar:sugar ratio as 1:1:1. Starting from the doublet at $\delta 4.78\left(\mathrm{H}-1^{\prime \prime \prime}\right)$ the observed crosspeak with the signal at $\delta 3.24$ in the DQF-COSY permitted assignment of $\mathrm{H}-2^{\prime \prime \prime}$. The chain of coupled protons, $\mathrm{H}-$ $2^{\prime \prime \prime}, \mathrm{H}-3^{\prime \prime \prime}, \mathrm{H}-4^{\prime \prime \prime}, \mathrm{H}-5^{\prime \prime \prime} \mathrm{A}$ and $\mathrm{H}-5^{\prime \prime \prime} \mathrm{B}$, was thereafter assigned after a sequential 'walk' in the same spectrum (Table 2). Subsequently the chemical shifts of the corresponding carbon atoms (Table 3) were assigned from the HSQC experiment, which together with the large ${ }^{1} \mathrm{H}-{ }^{1} \mathrm{H}$ coupling constants (Table 2 ) agreed with all the protons axial in a $\beta$-linked xylopyranoside. On the basis of a combination of COSY, TOCSY, HSQC, HMBC and SEFT NMR spectra it was possible to assign all the proton (Table 2) and carbon (Table $3)$ resonances of the other sugar moiety, which was determined to be a $\beta$-glucopyranoside. The crosspeak at $\delta 5.6 / 145.3\left(\mathrm{H}-1^{\prime \prime} / \mathrm{C}-3\right)$ in the HMBC spectrum revealed that this sugar was linked to the aglycone 3-position. The high-field position of the anomeric proton of the xylose unit $(\delta$ 4.78) indicated a sugar-sugar linkage. The pronounced downfield shift of C-2" $\left(\begin{array}{l}\delta \\ 82.25\end{array}\right)$ compared to the analogous C-2" signal of for instance the corresponding signal of $7(\delta$ 74.80) (Andersen, Aksnes, Nerdal \& Johansen, 1991), indicated that the xylosyl residue was connected to $\mathrm{C}-2^{\prime \prime}$ of the glucose ring. This linkage was confirmed by the crosspeak at $\delta$ 4.8/81.0 in the HMBC spectrum between $\mathrm{H}-1^{\prime \prime \prime}$ and C-2". Thus, the identity of 9 was found to be petunidin $3-O-\left(2^{\prime \prime}-O-\beta\right.$-xylopyranosyl- $\beta$-glucopyranoside), petunidin 3-O-sambubioside.

The proton and carbon shifts of 2, 6, 14 and 17 (Tables 2 and 3) were assigned by the same one- and two-dimensional homo- and heteronuclear NMR techniques as used for 9. They were found to contain the same sugar (3-sambubioside) and the corresponding aglycones were in accordance with delphinidin, cyanidin, peonidin and malvidin, respectively. Cyanidin 3$O$-sambubioside, 6, was also cochromatographed (HPLC and TLC) against authentic pigment isolated from Sambucus nigra (Andersen et al., 1991). Anthocyanidin disaccharides have not been identified in the genus Vaccinium previously, and the 3-sambubiosides of petunidin (9), peonidin (14) and malvidin (17) are novel compounds. 
Table 2

${ }^{1} \mathrm{H}$ NMR chemical shifts for the 3-sambubiosides of delphinidin (2), cyanidin (6), petunidin (9), peonidin (14) and malvidin (17)

\begin{tabular}{|c|c|c|c|c|c|}
\hline Aglycone & $\mathbf{2} \delta(\mathrm{ppm}) J(\mathrm{~Hz})$ & $\mathbf{6} \delta(\mathrm{ppm}) J(\mathrm{~Hz})$ & $9 \delta(\mathrm{ppm}) J(\mathrm{~Hz})$ & $14 \delta(\mathrm{ppm}) J(\mathrm{~Hz})$ & $17 \delta(\mathrm{ppm}) J(\mathrm{~Hz})$ \\
\hline 4 & $9.00 \mathrm{~s}$ & $9.05 \mathrm{~s}$ & $9.01 \mathrm{~s}$ & $9.10 \mathrm{~s}$ & $9.13 \mathrm{~s}$ \\
\hline 6 & $6.75 \mathrm{~d} 1.8$ & $6.75 \mathrm{~d} 2.0$ & $6.72 \mathrm{~d} 1.8$ & $6.76 \mathrm{~d} 1.8$ & $6.77 \mathrm{~d} 1.8$ \\
\hline 8 & $6.97 \mathrm{~d} 1.8$ & 6.99 d 1.5 & $6.96 \mathrm{~d} 1.8$ & $7.03 \mathrm{dd} 1.8,0.7$ & $7.06 \mathrm{~d} 1.5$ \\
\hline $2^{\prime}$ & $7.87 \mathrm{~s}$ & $8.14 \mathrm{~d} 2.4$ & $7.83 \mathrm{~d} 2.0$ & $8.16 \mathrm{~d} 2.2$ & $8.03 \mathrm{~s}$ \\
\hline $5^{\prime}$ & & $7.11 \mathrm{~d} 8.7$ & & $7.13 \mathrm{~d} 8.8$ & \\
\hline $6^{\prime}$ & $7.87 \mathrm{~s}$ & $8.37 \mathrm{dd} 2.3,8.6$ & 7.92 d 2.0 & $8.47 \mathrm{dd} 8.6,2.2$ & $8.03 \mathrm{~s}$ \\
\hline $\mathrm{OMe}$ & & & $4.08 \mathrm{~s}$ & $4.11 \mathrm{~s}$ & $4.09 \mathrm{~s}$ \\
\hline \multicolumn{6}{|c|}{ 3-O- $\beta$-glucoside } \\
\hline $1^{\prime \prime}$ & $5.55 \mathrm{~d} 7.7$ & $5.54 \mathrm{~d} 7.6$ & $5.56 \mathrm{~d} 7.7$ & $5.55 \mathrm{~d} 7.7$ & $5.57 \mathrm{~d} 7.7$ \\
\hline $2^{\prime \prime}$ & $4.07 \mathrm{dd} 7.7,9.0$ & $4.05 \mathrm{dd} 7.7,9.0$ & $4.09 \mathrm{dd} 7.7,9.4$ & $4.00 \mathrm{dd} 7.7,9.0$ & $3.96 \mathrm{dd} 7.7,9.0$ \\
\hline $3^{\prime \prime}$ & $3.86+9.2$ & 3.86 t 9.2 & 3.87 t 9.0 & 3.87 t 9.0 & 3.86 t 9.0 \\
\hline $4^{\prime \prime}$ & $3.61 \mathrm{dd} 9.5,9.4$ & 3.58 dd $9.5,9.4$ & $3.57 \mathrm{dd} 9.6,9.5$ & 3.56 dd $9.5,9.4$ & 3.55 dd $9.5,9.0$ \\
\hline $5^{\prime \prime}$ & $3.65 \mathrm{~m}$ & 3.67 ddd $9.5,5.9,2.0$ & $3.67 \mathrm{~m}$ & 3.66 ddd $9.5,6.1,2.2$ & 3.65 ddd $9.5,5.1,2.6$ \\
\hline $6^{\prime \prime} \mathrm{A}$ & $4.00 \mathrm{dd} 2.2,12.3$ & $4.00 \mathrm{dd} 2.2,12.3$ & $3.99 \mathrm{dd} 2.2,12.3$ & $3.99 \mathrm{dd} 2.2,12.1$ & $3.99 \mathrm{dd} 2.2,12.1$ \\
\hline $6^{\prime \prime} \mathrm{B}$ & 3.82 dd $5.7,12.1$ & 3.81 dd $5.9,12.3$ & $3.81 \mathrm{dd} 6.1 \quad 12.3$ & 3.79 dd $6.1,12.3$ & 3.78 dd $6.1,12.1$ \\
\hline \multicolumn{6}{|c|}{$2^{\prime \prime}-O$-xylosyl } \\
\hline $1^{\prime \prime \prime}$ & $4.77 \mathrm{~d} 7.6$ & $4.84 \mathrm{~d} 7.6$ & $4.78 \mathrm{~d} 7.5$ & $4.84 \mathrm{~d} 7.5$ & $4.77 \mathrm{~d} 7.5$ \\
\hline $2^{\prime \prime \prime}$ & $3.25 \mathrm{dd} 7.7,9.0$ & $3.26 \mathrm{dd} 7.7,9.0$ & $3.24 \mathrm{dd} 7.7,9.0$ & $3.23 \mathrm{dd} 7.7,9.0$ & $3.20 \mathrm{dd} 7.5,8.8$ \\
\hline $3^{\prime \prime \prime}$ & 3.37 t 9.0 & $3.38 \mathrm{~m}$ & 3.36 t 9.0 & $3.38+9.0$ & $3.35 \mathrm{t} 8.8$ \\
\hline $4^{\prime \prime \prime}$ & 3.43 ddd $9.0,10.5,5.3$ & 3.48 ddd $9.0,10.5,5.5$ & 3.42 ddd $9.0,10.5,5.3$ & 3.47 ddd $8.8,10.5,5.5$ & $3.44 \mathrm{~m}$ \\
\hline $5^{\prime \prime \prime} \mathrm{A}$ & 3.68 ddd $9.5,5.7,2.4$ & 3.76 dd $5.5,11.6$ & 3.68 ddd $9.7,6.1,2.2$ & 3.75 dd $5.3,11.9$ & 3.74 dd $5.3,11.6$ \\
\hline $5^{\prime \prime \prime} \mathrm{B}$ & $3.04 \mathrm{dd} 10.5,11.6$ & 3.14 dd $10.6,11.4$ & 3.06 dd $10.3,11.6$ & 3.13 dd $10.5,11.6$ & 3.03 dd $9.9,11.6$ \\
\hline
\end{tabular}

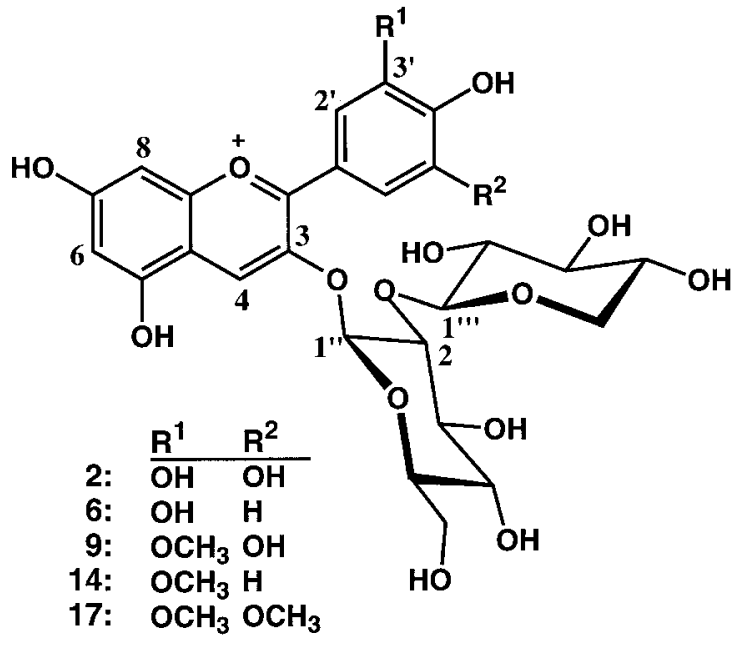

\section{Experimental}

\subsection{Plant material}

Ripen berries of Uveira, $V$. padifolium (syn. V. madeneuse) were collected in Madeira island (Portugal) in October 1995 and stored at $-20^{\circ} \mathrm{C}$. The berries $(100 \mathrm{~g})$ were extracted 10 times with $100 \mathrm{ml} \mathrm{MeOH}$ containing $1 \%$ TFA. The combined extract was filtered, concen- trated under reduced pressure, partitioned against ethyl acetate, and applied on an Amberlite XAD-7 column. The dried extract $(1.0 \mathrm{~g})$ was fractionated by a Sephadex LH-20 column $(1000 \times 50 \mathrm{~mm})$ using a step elution with $20-60 \% \quad \mathrm{MeOH}-\mathrm{H}_{2} \mathrm{O} \quad(0.1 \% \quad$ TFA $)$. Fractions were further separated by semi-preparative HPLC.

\subsection{Chromatography}

High performance liquid chromatography (HPLC) was performed on a HP-1050 module system (Hewlett Packard $)$ using an ODS Hypersil column $(200 \times 4.6$ $\mathrm{mm}, 5 \mu \mathrm{m})$ and diode array detection. Two solvents were used for elution: $\mathrm{A}, \mathrm{HCO}_{2} \mathrm{H}-\mathrm{H}_{2} \mathrm{O}(1: 9, \mathrm{v} / \mathrm{v}) ; \mathrm{B}$, $\mathrm{MeOH}-\mathrm{HCO}_{2} \mathrm{H}-\mathrm{H}_{2} \mathrm{O}(5: 1: 4, \mathrm{v} / \mathrm{v})$. The elution profile was $0-4 \mathrm{~min}, 10 \% \mathrm{~B}$ in $\mathrm{A}$ (isocratic); 4-21 min, 10$100 \% \mathrm{~B}$ in $\mathrm{A}$ (linear gradient), $100 \% \mathrm{~B}$ (isocratic). The

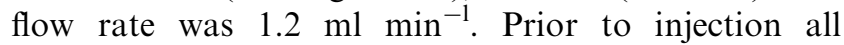
samples were filtered through a $0.45 \mu \mathrm{m}$ Millipore membrane filter. Thin layer chromatography was carried out on microcrystalline cellulose $\mathrm{F}$ (Merck, art. 5556) with the solvents $1-\mathrm{BuOH}-\mathrm{HOAc}-\mathrm{H}_{2} \mathrm{O}$ (4:1:5, upper phase) and $\mathrm{HCO}_{2} \mathrm{H}-$ conc. $\mathrm{HCl}-\mathrm{H}_{2} \mathrm{O}$ (1:1:2).

\subsection{Spectroscopy}

UV-VIS absorption spectra were recorded on-line 
Table 3

${ }^{13} \mathrm{C}$ NMR chemical shifts for the 3-sambubiosides of delphinidin (2), cyanidin (6), petunidin (9) and peonidin (14) isolated from the blue berries of Vaccinium padifolium ${ }^{\mathrm{a}}$

\begin{tabular}{|c|c|c|c|c|}
\hline Aglycone & $\mathbf{2} \delta(\mathrm{ppm})$ & $6 \delta(\mathrm{ppm})$ & $\mathbf{9} \delta(\mathrm{ppm})$ & $\mathbf{1 4} \delta(\mathrm{ppm})$ \\
\hline 2 & 164.27 & 164.26 & 164.14 & 164.36 \\
\hline 3 & 145.54 & 145.30 & 145.41 & 145.34 \\
\hline 4 & 135.54 & 136.31 & 136.45 & 137.10 \\
\hline 5 & 159.16 & 159.36 & 159.22 & 159.36 \\
\hline 6 & 103.33 & 103.40 & 103.43 & 103.43 \\
\hline 7 & 170.23 & 170.44 & 170.59 & 170.72 \\
\hline 8 & 94.98 & 95.09 & 95.20 & 95.27 \\
\hline 9 & 157.55 & 157.62 & 157.67 & 157.84 \\
\hline 10 & 113.09 & 113.23 & 113.34 & 113.49 \\
\hline $1^{\prime}$ & 120.06 & 121.28 & 119.94 & 121.15 \\
\hline $2^{\prime}$ & 112.76 & 118.55 & 108.68 & 114.79 \\
\hline $3^{\prime}$ & 147.58 & 147.47 & 149.88 & 149.72 \\
\hline $4^{\prime}$ & 144.69 & 155.80 & 147.32 & 156.67 \\
\hline $5^{\prime}$ & 147.58 & 117.40 & 145.10 & 117.79 \\
\hline $6^{\prime}$ & 112.76 & 128.64 & 114.75 & 130.02 \\
\hline $\mathrm{OMe}$ & & & 57.20 & 56.91 \\
\hline \multicolumn{5}{|c|}{ 3-O- $\beta$-glucoside } \\
\hline $1^{\prime \prime}$ & 101.72 & 101.62 & 102.12 & 102.06 \\
\hline $2^{\prime \prime}$ & 82.60 & 81.79 & 82.25 & 81.59 \\
\hline $3^{\prime \prime}$ & 77.94 & 78.20 & 77.99 & 78.22 \\
\hline $4^{\prime \prime}$ & 70.68 & 70.79 & 70.78 & 70.85 \\
\hline $5^{\prime \prime}$ & 78.66 & 78.73 & 78.76 & 78.85 \\
\hline $6^{\prime \prime}$ & 62.23 & 62.28 & 62.28 & 62.32 \\
\hline \multicolumn{5}{|c|}{$2^{\prime \prime}-O$-xylosyl } \\
\hline $1^{\prime \prime \prime}$ & 106.10 & 105.76 & 105.74 & 105.48 \\
\hline $2^{\prime \prime \prime}$ & 75.78 & 75.70 & 75.63 & 75.59 \\
\hline $3^{\prime \prime \prime}$ & 77.72 & 77.84 & 77.64 & 77.75 \\
\hline $4^{\prime \prime \prime}$ & 70.85 & 70.98 & 70.84 & 70.98 \\
\hline $5^{\prime \prime \prime}$ & 67.05 & 67.19 & 66.93 & 67.11 \\
\hline
\end{tabular}

${ }^{a}$ The shift values are determined from the SEFT spectrum.

during HPLC analysis using a photodiode array detector (HP 1050, Hewlett Packard). When the UV-VIS absorption spectra were measured in $0.01 \% \mathrm{HCl}-$ $\mathrm{MeOH}$, the following $\lambda_{\text {Vis.max }}(\mathrm{nm})$ and $A_{440} / A_{\text {Vis.max }}$
(\%) data were obtained for the five anthocyanidin 3sambubiosides: 2, $540 \mathrm{~nm}$ (18\%); 6, $530 \mathrm{~nm}(23 \%)$; 9, $538 \mathrm{~nm}(19 \%) ; 14,526 \mathrm{~nm}(29 \%) ; 17,536 \mathrm{~nm}(24 \%)$. Spectral measurements were made over the wavelength range $240-600 \mathrm{~nm}$ in steps of $2 \mathrm{~nm}$. The relative quantitative data were based on the average values of the absorptions on every second $\mathrm{nm}$ between 500 and 540 $\mathrm{nm}$, without taking into account the different molar absorption coefficients of the pigments. The NMR experiments (DQF-COSY, TOCSY, HSQC, HMBC, SEFT) were obtained at $600.13 \mathrm{MHz}$ and $150.92 \mathrm{MHz}$ for ${ }^{1} \mathrm{H}$ and ${ }^{13} \mathrm{C}$, respectively, on a Bruker DRX-600 instrument at $25^{\circ} \mathrm{C}$. The deuteriomethyl ${ }^{13} \mathrm{C}$ signal and the residual ${ }^{1} \mathrm{H}$ signal of the solvent $\left(\mathrm{CF}_{3} \mathrm{CO}_{2} \mathrm{D}-\right.$ $\left.\mathrm{CD}_{3} \mathrm{OD} ; 5: 95, \mathrm{v} / \mathrm{v}\right)$ were used as secondary references ( $\delta 49.0$ and 3.4 from TMS, respectively).

\section{Acknowledgements}

LC is grateful to Mr Victor Freitas (Univ. Madeira) for collecting berries of Vaccinium padifolium and to FCT (Fundação para a Ciência e Tecnologia, Portugal) for a PRAXIS XXI BD scholarship.

\section{References}

Andersen, Ø. M. (1987). Phytochemistry, 26, 1220.

Andersen, Ø. M., Helland, D. E. (1995). Use of anthocyanidin and anthocyanidin derivatives (PCT/NO/00185).

Andersen, Ø. M., Aksnes, D. W., Nerdal, W., \& Johansen, O.-P. (1991). Phytochem. Anal., 2, 175.

Ballinger, W. E., Galetta, G. J., \& Mannes, E. P. J. (1979). Am. Soc. Hort. Sci., 104, 554.

Gao, L., \& Mazza, G. (1995). J. Liquid Chromatogr., 18, 245.

Morazzoni, P., \& Bombardelli, E. (1996). Fitoterapia, 67, 3.

Rivera, D., \& Obón, C. (1995). J. Ethnopharmacol., 46, 73.

Vieira, R. (1992). O interesse das plantas endémicas Macaronésicas, SNPRCN, p. 137. 